\title{
Practical notes on ultraviolet technical photography for art examination
}

\author{
Antonino Cosentino \\ Cultural Heritage Science Open Source, chsopensource.org. Piazza Cantarella 11, Aci Sant'Antonio, 95025, Italy \\ antoninocose@gmail.com
}

\begin{abstract}
This paper discusses two technical photographic methods based on the use of ultraviolet sources for art examination: ultraviolet fluorescence (UVF) and ultraviolet reflectance (UVR). While the UVF technique can be carried out with any digital camera, UVR images are acquired with a digital camera modified to be full spectrum, and thus sensitive into the UV region of the spectrum until about $360 \mathrm{~nm}$. This modification involves the removal of the in-built hot mirror filter on the CCD or CMOS sensor, rendering it sensitive to ultraviolet and infrared radiation. This paper illustrates the procedures and the equipment needed for these technical photographic methods, discussing case studies and results on prepared samples.
\end{abstract}

Notas práticas sobre a fotografia de ultravioleta para o exame de obras de arte

\section{Resumo}

Este artigo discute dois métodos fotográficos baseados no uso da radiação ultravioleta para o exame de obras de arte: a fluorescência de ultravioleta (UVF) e a reflectância de ultravioleta (UVR). Enquanto a fotografia de UVF pode ser efectuada com qualquer máquina fotográfica digital, as imagens de UVR são adquiridas com uma máquina fotográfica digital modificada para espectro completo, sensível à radiação ultravioleta com comprimento de onda até cerca de $360 \mathrm{~nm}$. Esta modificação envolve a remoção do filtro interno sobre o sensor CCD ou CMOS de forma a tornar a máquina sensível à radiação ultravioleta e infravermelha. Este artigo descreve os procedimentos e o equipamento necessários para a realização desses exames, discutindo quer estudos de casos quer os resultados obtidos com amostras preparadas com esse objectivo.

\section{Keywords}

Ultraviolet fluorescence photography Ultraviolet reflectance photography Technical photography

\section{Palavras-chave}

Fotografia de fluorescência de ultravioleta Fotografia de reflectância de ultravioleta Fotografia técnica 


\section{Introduction}

Technical Photography (TP) for art diagnostics corresponds to the collection of broadband spectral images acquired with a modified full spectrum digital camera, using different illumination sources and filters. In addition to capturing visible light, the silicon-based CCD or CMOS cameras respond both to the nearinfrared and near-ultraviolet ranges of the spectrum (between about 360 and $1100 \mathrm{~nm}$ ). Manufacturers install an UV/IR cut-off filter in front of the sensor to reduce the acquisition of transmitted infrared and ultraviolet radiation. Specialized companies can remove this filter and then the camera is said to be modified full spectrum. The full-spectrum camera may then be used successfully to acquire broadband images in the infrared and ultraviolet regions, which can reveal information such as underdrawing, pentimenti and retouches in paintings [1-4]; enhance the reading of faded wall paintings [5]; or be used for archaeological documentation [6]. These technical photos can also provide preliminary spectral information regarding the identification of materials [7] based on their characteristic response in the different radiation wavebands. Even if the conclusions that can be drawn from these images are qualitative and not absolutely conclusive, this methodology is getting a lot of interest in the art conservation field because it is simple and relatively affordable, thus making it an ideal first step for pigment identification, before other techniques are carried out. This paper discusses technical photography methods that use UV radiation sources: UV fluorescence (UVF) and UV reflectance (UVR). As long as the UV dosage is kept within a reasonable limit [8], these methods can be considered safe and non-invasive and can be used to characterize painting materials; to evaluate the current state of conservation and prior treatment history of an artwork; and to identify retouches on polychrome art. It must be noted that UVF is also known as UV induced visible fluorescence. Both terms are descriptive of the phenomenon and the second is simply more detailed. This paper illustrates recent applications together with recommendations for the photographic equipment and procedures that take into account the latest technological developments. However, this paper does not address the interpretation of the actual fluorescence of art materials. Other studies have discussed UV fluorescence spectra of painting material (pigments, dyes, media and varnishes) [9-11] and provide useful resources to conservators and conservation scientists in their interpretation of the UVF images. Nevertheless, it must be taken into account that the spectral emission of commonly fluorescent artists' materials can be highly modified by the presence of other surrounding materials. Optical emitted radiation can interact with surrounding matter, giving rise to selective absorption and scattering phenomena [12].

\section{Experimental}

\section{UV radiation sources}

For the documentation of paintings, a lamp power output of around $50 \mu \mathrm{W} / \mathrm{cm}^{2}$ is recommended so that the shooting exposure is limited to a few seconds and there are no damages to the artworks [13]. This radiation is much less than the natural UVA radiation from the sun which is in the range $500-1500 \mu \mathrm{W} / \mathrm{cm}^{2}$ [8]. The typical practice for conservation studios was to use UV fluorescent tubes. They are very cheap and can be mounted on commercial fixtures for normal visible light fluorescent tubes, provided that the support is not UV fluorescent itself. These tubes are very economical, and as many as
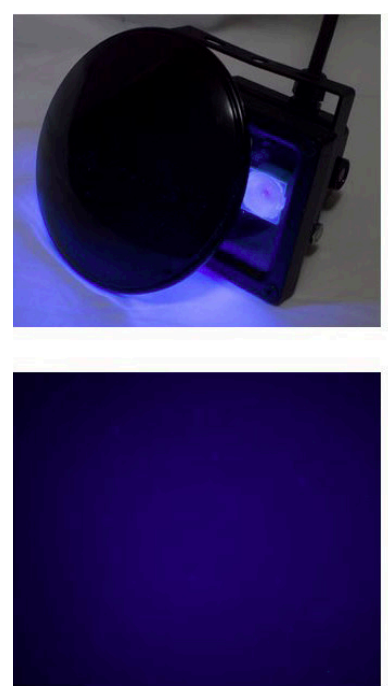

UV LEDS

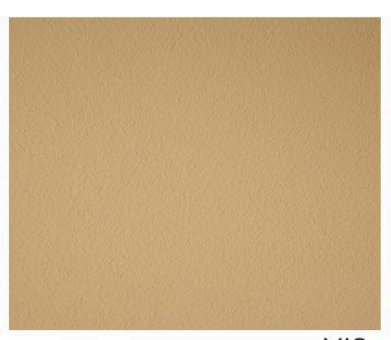

VIS

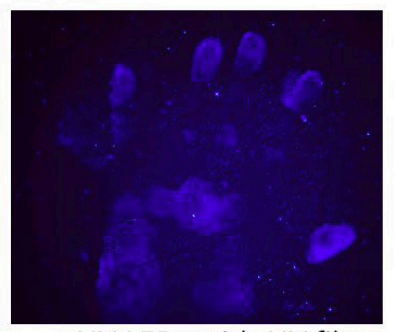

UV LEDs with UV filter

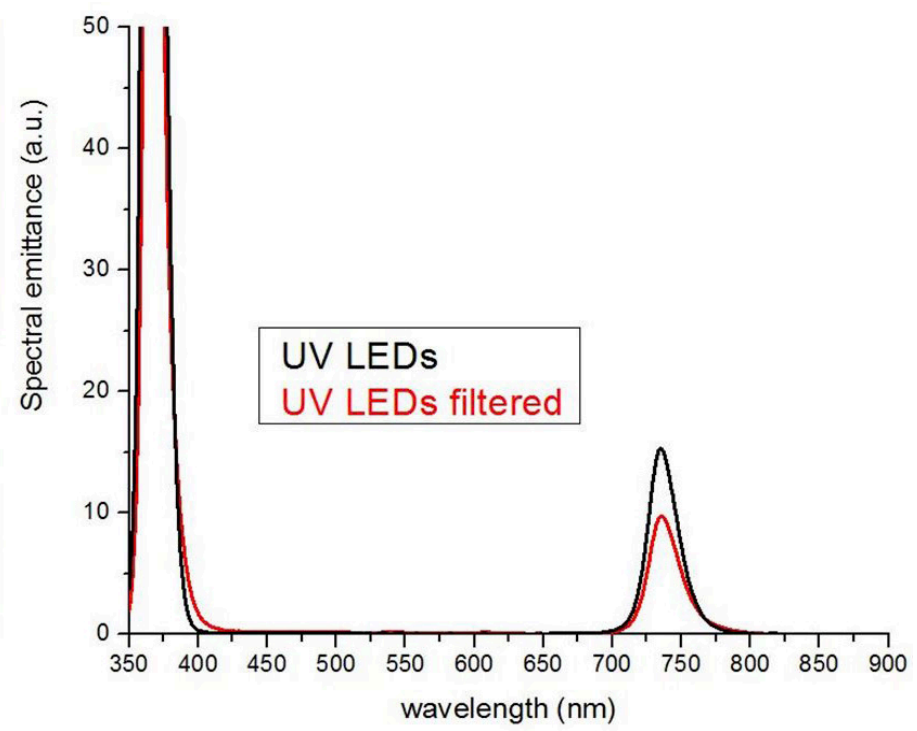

Figure 1. UV LED lamps must be filtered with a UV-pass filter to cut off the purple visible emission, which would otherwise limit their utility for UV technical photography. Emittance spectra show the violet component of the LED is cut off. A fingerprint on the wall becomes visible only when the UV-pass filter is applied on the lamp. 

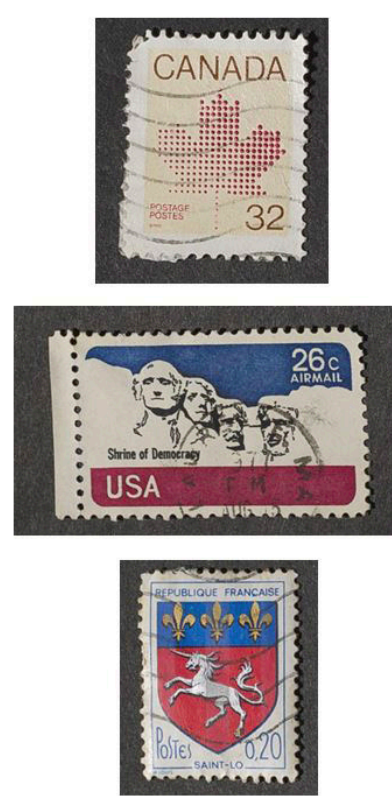

VIS
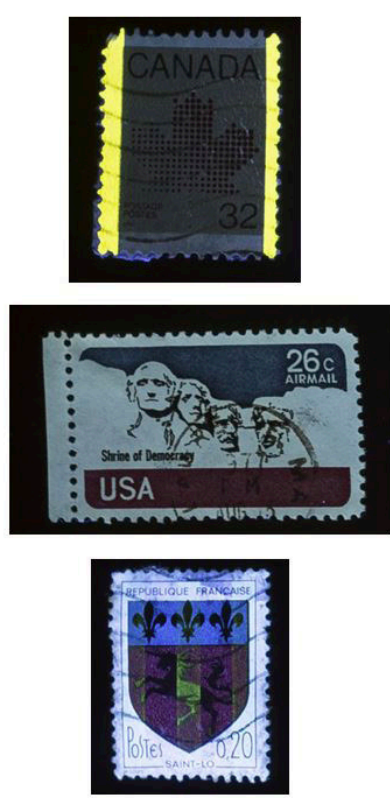

UVF
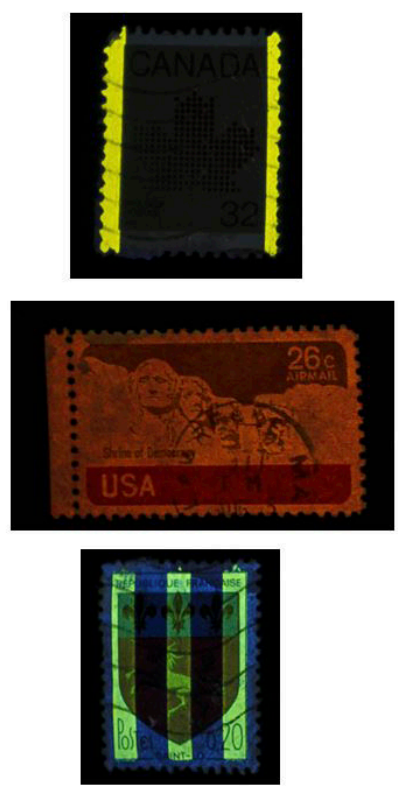

UVF 254

Figure 2. In the late ' 50 s, postage stamps from countries such as the UK, France and the USA were coated with phosphors in order to automate the postal sorting and cancelling. There are two Ultraviolet wavelengths used for the examination of stamps. Long-wave (UVF at $365 \mathrm{~nm}$ ) is used to detect alterations, damages and repairs. Phosphors are best viewed in shortwave ultraviolet radiation (UVF254). While the Canadian stamp (upper row) shows the yellow fluorescence of its phosphor with both UVF and UVF254, the US and French stamps show orange and green phosphors, respectively, only in the UVF254 photo.

are needed can be used to provide the UV illumination necessary for studio photography. The important drawback is that since the surface of the tubes is very large they cannot be practically filtered in order to cut off the visible violet light and the infrared radiation that is also produced. This has been a condition accepted by most conservation studios, especially since the examination was limited to detect inpaints (which generally will look darker than old paints and varnishes). On the other hand, the violet light will not adequately allow for the subtle UV fluorescence colors from old paints and varnishes to be fully appreciated. An alternative to the tube lamps is a forensic UV spotlight lamp, mounting a mercury vapor lamp (in the range of $150 \mathrm{~W}$ ) with internal ballast and a UV pass filter, providing excellent filtration. Indeed, since this is a spotlight, illumination is not uniform over the painting area, so a "light painting" technique is necessary. To solve this, the lamp is shone over the painting during a long exposure, in order to have a final UV image that has been uniformly exposed.

It is often necessary to document works of art of large dimensions with ultraviolet photography, either UVF and/ or UVR. In this case, the panoramic photographic method $[14,15]$ can be implemented.

However, the UV lamps often provide uneven and insufficient illumination for large surfaces. In this case, the panoramic method must be coupled with the light painting technique, using a spotlight UV lamp along with the panoramic head.

For UV photography (UVF and UVR) the high flux Nichia $365 \mathrm{~nm}$ LED lamps are recommended. They have the same UV radiation quality of the forensic lamps but with more advantages. They turn on instantly, do not heat up, and they are very lightweight and sturdy. These LEDs must be filtered to cut out the violet light output with a UV-pass glass analogous to the BW 403 filter (Figure 1). On the other hand, there are also UV LEDs available from other brands (e.g. Roithner), which output a very narrow UV band and no violet contamination.

The UV lamps mentioned so far have a main emission peak at $365 \mathrm{~nm}$. UV fluorescence can also be induced with lamps emitting at $254 \mathrm{~nm}$, and this method is called UVF254. These lamps must be used with extreme care since this UV range (UVC) is dangerous for the eyes and skin. Illumination with a $254 \mathrm{~nm}$ UV lamp produces fluorescence in molecules not excited by the $365 \mathrm{~nm}$ UV lamp (Figure 2), and this technique allows these events to be observed.

\section{Camera and photo calibration}

For VIS (visible) and UV fluorescence photography the camera is calibrated with the X-rite ColorChecker Passport, the industry standard color reference target for creating DNG profiles for color management so specific colors may be evaluated. Due to differences in technologies and variables in manufacturing processes every camera captures colors a bit differently and must undergo custom calibration. The images are shot in camera RAW format and they are then color corrected using the DNG camera profile mentioned above. The American Institute of Conservation Photo 


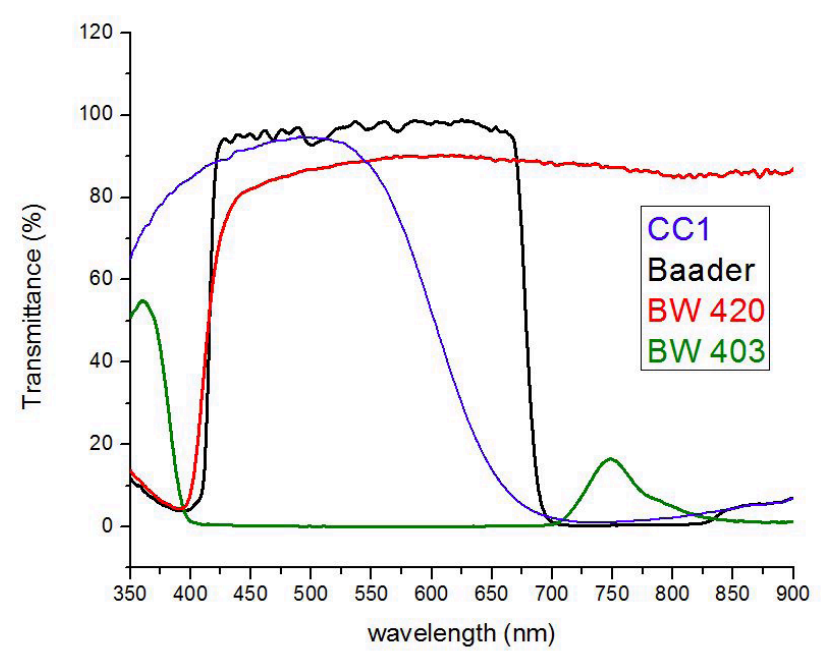

Figure 3. Transmittance curves of the three filters used for UVF and UVR photography.

Documentation (AIC $\mathrm{PhD}$ ) target [16] is also captured along with the work of art and it is used for white balancing VIS photography. Color calibration for ultraviolet fluorescence (UVF and UVF254) is trickier as there is not yet an officially recognized reference standard. As an aid for color balancing, and in order to guarantee reproducibility of the UVF photos, the AIC PhD target is accompanied by three emitters activated by UV lamps: a section of a card for forensic UV photography (orange fluorescence), a swatch of zinc white (yellow fluorescence), and a fluorescent paint (green fluorescence). These three UV emitters, together with the red fluorescence emission of the red swatch of the AIC $\mathrm{PhD}$ target, are used for color calibration of UVF and UVF254 photos. This is performed on the RAW files by editing them with Adobe Camera RAW software and assigning the appropriate Temperature and Tint. The UV fluorescence images are also exposure corrected using the red fluorescence of the red patch: Red channel $70 \pm 5$, Green 0, Blue 0 .

The AIC PhD target is also used to exposure correct the UVR image. Its grey patches are identified by the following designations (white to black): white; N8; N6.5; N5; N3.5; and black. The N8 patch is used to exposure correct the UVR image (RGB $50 \pm 5$ ).

\section{Filters}

For the two ultraviolet photography methods illustrated in this paper a set of three filters was used, and Figure 3 shows their transmittance curves. Other than the proposed filter set, many other possible combinations currently exist to obtain similar results. This set was selected based on an optimization to select better quality filters relative to their cost. Figure 4 shows the experimental setup to perform UVF and UVR photography, indicating the position of the camera and the lamps, and the filters used. UVF photography uses two filters - the X-Nite CC1 coupled with the BW 420. The $\mathrm{CC} 1$ is necessary to cut off any infrared radiation produced by the UV lamp. X-Nite $\mathrm{CC} 1$ belongs to the hot mirror class of filters, including the BW 486 and Heliopan BG38. They are used to stop the infrared but usually allow some UV. Therefore they cannot be used alone for UVF photography; otherwise the images acquire a purple cast. Indeed, a full spectrum camera becomes sensitive to UV radiation, and therefore the reflected UV radiation must be shielded from the sensor, otherwise the images will be dominated by the purple color associated to the UV radiation that is picked up by the red and blue channels. The BW 420 is a UV cut-off filter necessary to stop the UV reflected by the subject and passed by the X-Nite CC1. If it is necessary to make close up UVF photography, the BW 420 is not suitable because it also fluoresces under UV radiation. It is therefore necessary to substitute it with the UV/
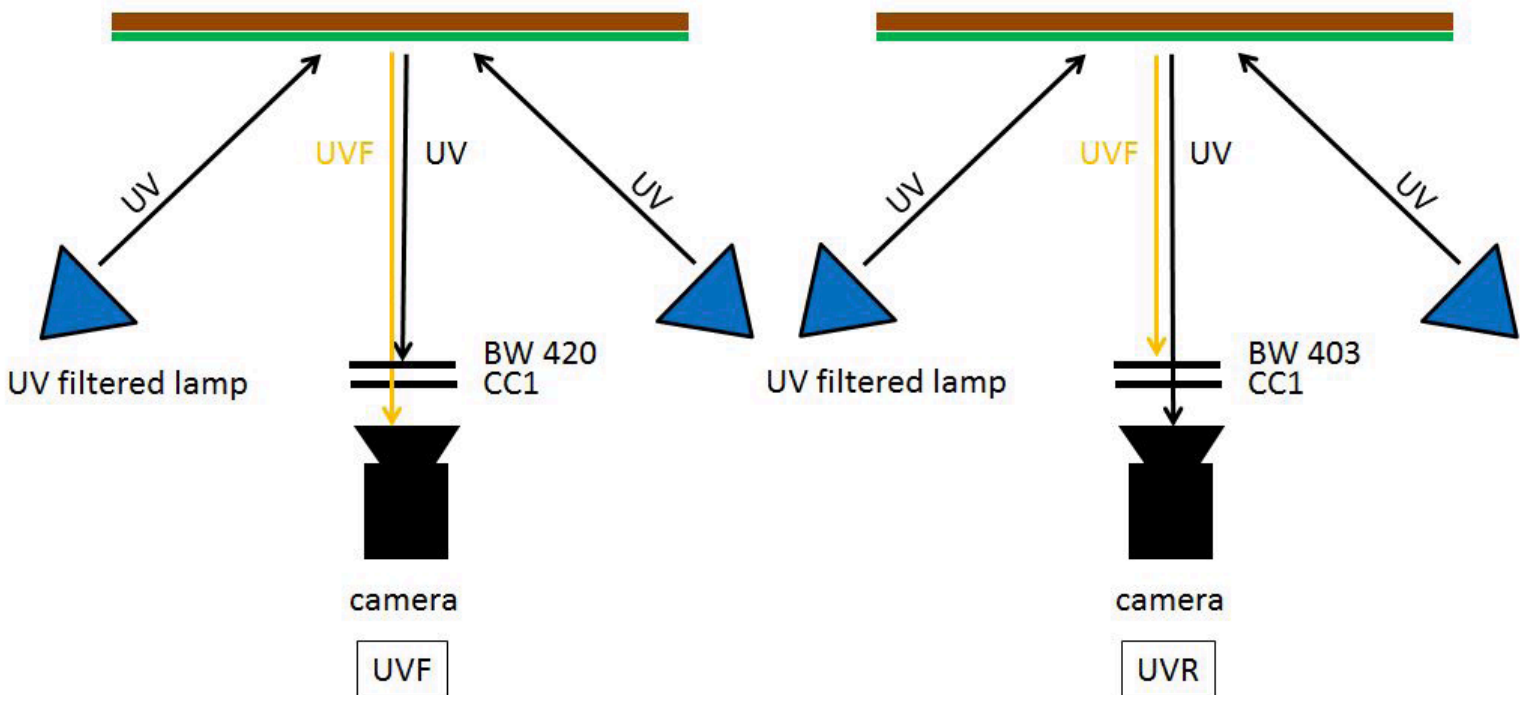

Figure 4. Experimental setup for the two ultraviolet photographic methods, UVF and UVR. 


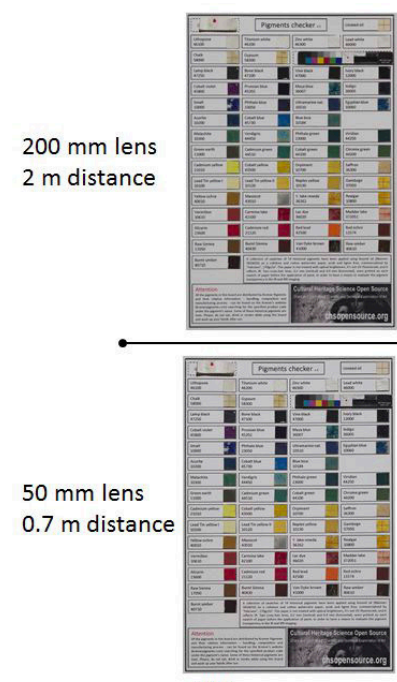

VIS
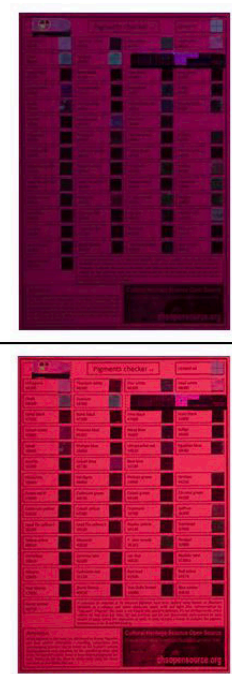

UVF CC1
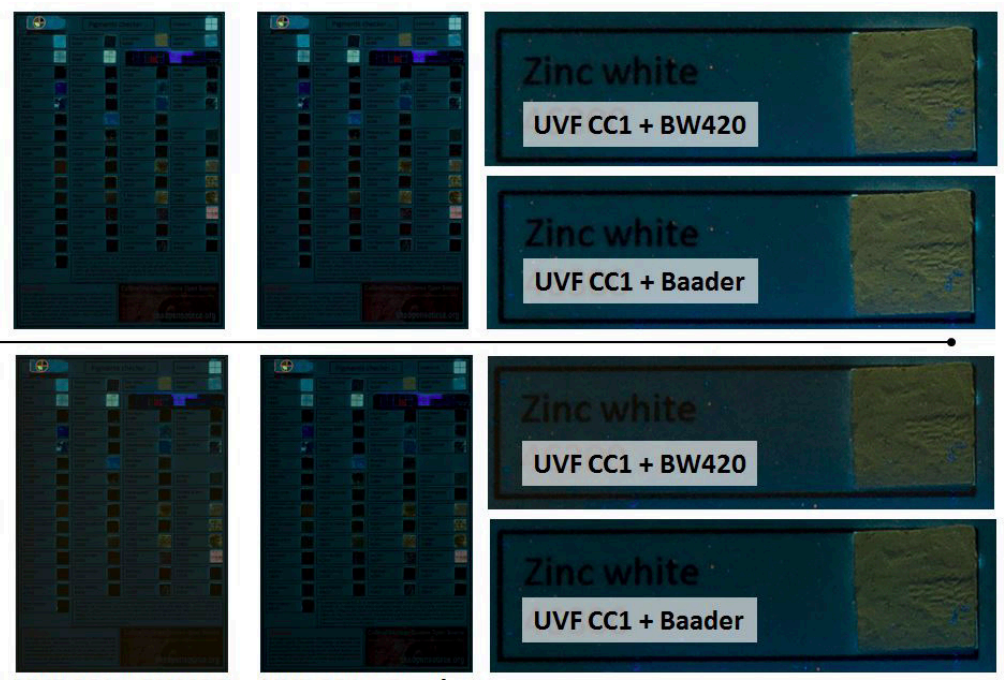

UVF CC1 + BW420
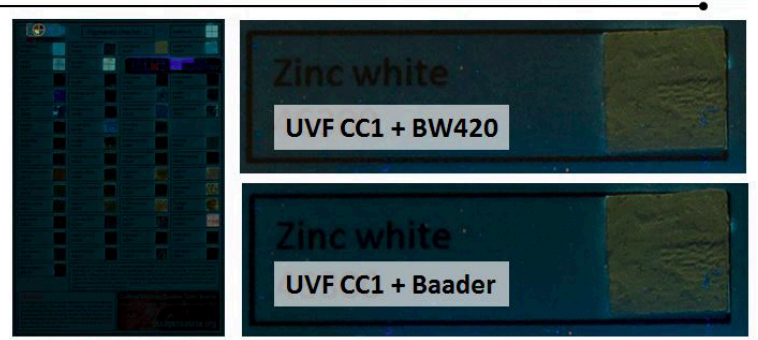

UVF CC1 + Baader

Figure 5. Pigments checker, collection of 54 historical pigments swatches. In the top row, images were taken with a $200 \mathrm{~mm}$ (f/8) lens at a $2 \mathrm{~m}$ distance. A $50 \mathrm{~mm}(\mathrm{f} / 8)$ lens at a $0.7 \mathrm{~m}$ distance was used for the bottom row. The lamp and the subject remained in the same relative position and only the camera was moved forward. UVF CC1 are the images taken with only the X-Nite CC1 filter and they are purple due to the UV radiation having been reflected into the camera and detected by the CMOS sensor. UVF CC1 images are also out of focus because the reflected UV dominates the images, and the lens was focused on the VIS instead. Once the BW420 or the UV/IR Baader filter is added, it becomes possible to photograph the actual UV fluorescence by canceling the noise brought by the reflected UV radiation. The images at $0.7 \mathrm{~m}$ are slightly affected by the yellow fluorescence of the BW 420 filter, as shown in the detail of the zinc white swatch (far right).

IR Baader filter [17] which has the same transmittance curve but does not emit any fluorescence. If the picture is taken from a distance and the UV lamps are kept at a close angle, the reflected UV that hits the BW 420 filter is only a small fraction of the total UV fluorescence, and so the fluorescence produced by the filter does not affect the final image. On the other hand, if a close up UVF photo is taken, the amount of UV hitting the filter could have considerable adverse effects on image quality (Figures 5-6). The absorbing filters, such as BW 420 and Kodak Wratten gelatins, typically show a fluorescence emission induced by the absorbed UV radiation. On the other hand, reflective filters which exploit radiation interference by multi-layer coatings typically do not suffer from these problems, although they are more expensive. For UVR, a UV-pass filter, the BW 403, is coupled to the $\mathrm{X}$-Nite CC1 to stop possible infrared radiation from the lamp or the environment. This filter does not produce any fluorescence and can be used on close-up photography.

\section{Lenses}

For UV reflectance photography old lenses often perform better, since the new ones can have optical acrylic elements and "anti-reflective" lens coatings which can significantly cut UV radiation. It must be mentioned that specialized and costly UV lenses exist and are mainly used for applications in forensics, science, and fine art photography. These are made of quartz or calcium fluoride and effectively transmit and focus UV radiation. On the other hand, there is no special lens requirement for UVF photography, since this technique involves capturing the visible region of the spectrum, and a normal photographic lens can be used without any issues. It is recommended to use fixed focal lenses and avoid complex lenses, as they are likely to give out flares in the ultraviolet reflectance photography. It is also recommended to avoid telephoto lenses over $200 \mathrm{~mm}$, so that the lens will be fast enough to work with the low-intensity emission produced in UV fluorescence imaging. It must be noted that after shooting a VIS photo, it is necessary to refocus for UVR photography since UV radiation is focused on a different focal plane than that of visible light.
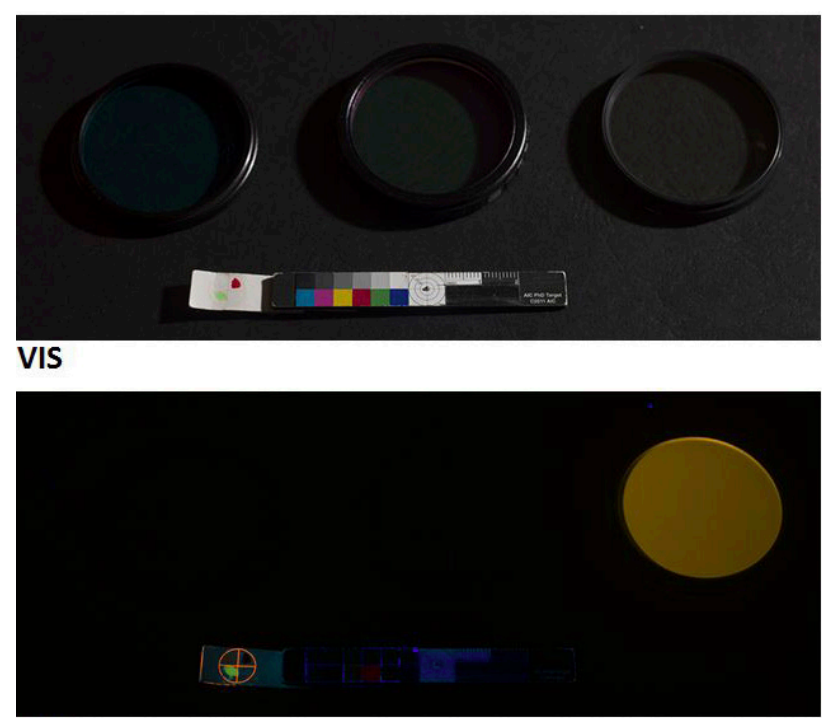

\section{UVF}

Figure 6. The UV induced fluorescence of the BW420 filter becomes apparent when the filter is photographed under UV radiation. For close-up photos, the UV/IR Baader filter is strictly recommended. 


\section{Information provided by the photographs and its interpretation}

\section{Ultraviolet fluorescence}

UV fluorescence describes the emission of visible light observed when an electron of a molecule or atom that has been excited to a higher energy state by UV radiation relaxes to its ground state, emitting a photon with energy associated to the difference between the two states. The emission induced on polychrome artworks depends on many factors: the wavelength and bandwidth of the UV source, the painting materials (pigments, dyes, binders, varnishes) and how all of these materials interact with each other and, additionally, how they have aged. UVF is used for the examination of different kinds of historical and archaeological objects [18], including photographs [19] and textiles [20], but it is most widely used for polychrome art. UV fluorescence can indeed be used for a preliminary identification of pigments [21-23]. However, the varnish does play a major role, since it generally exhibits a strong fluorescence which can overwhelm
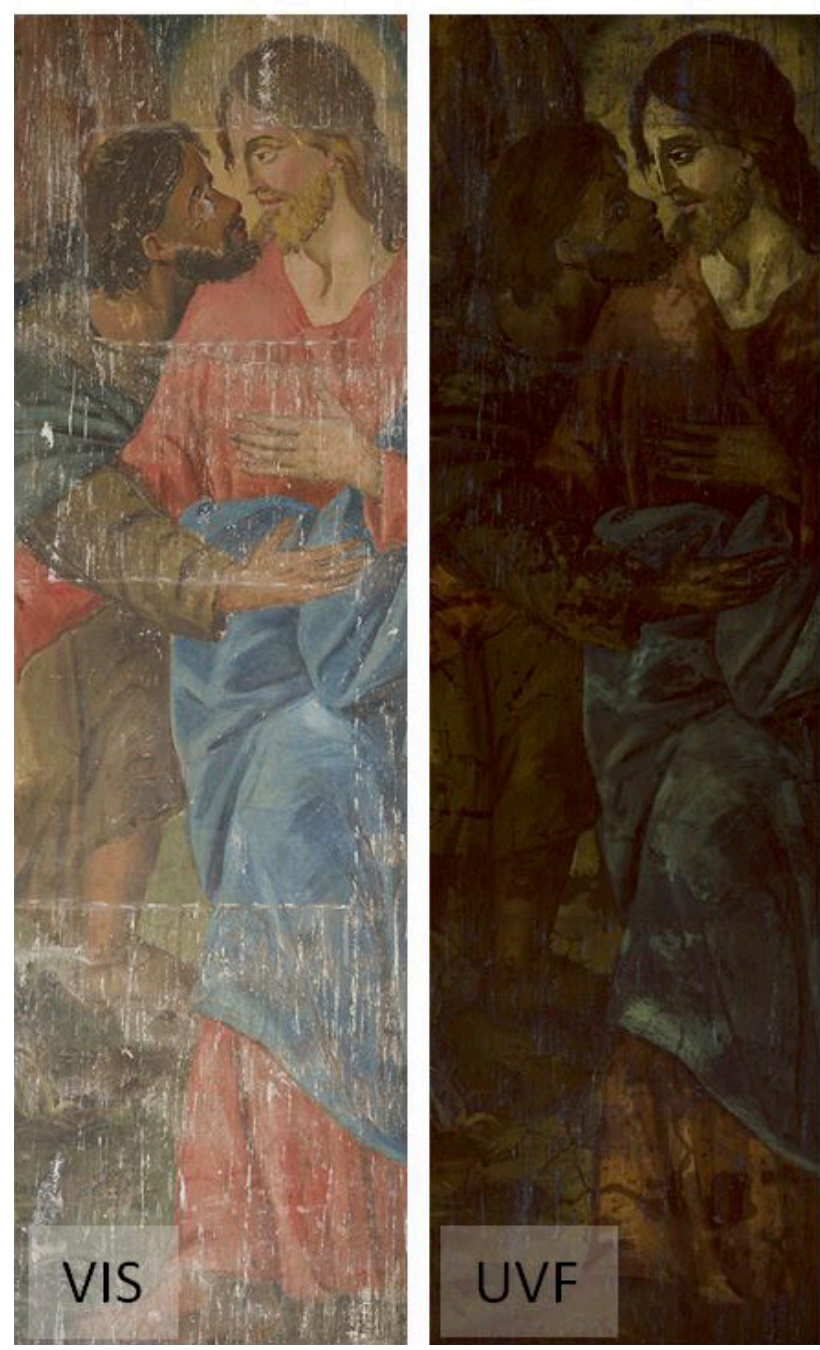

Figure 7. Crucifix chapel, Aci Sant'Antonio (Sicily). The $a$ secco technique is suggested by the intense UV fluorescence. the actual fluorescence of the pigments. Consequently, UVF documentation aiming at pigments identification is recommended only when the varnish has been removed from the artwork. UVF photography must always be seen as a supplementary technique for pigment identification, since this method can only provide qualitative information on the UV-induced visible fluorescence of materials. For quantitative studies, the UV fluorescence must instead be documented with fluorescence spectroscopy and colorimetric measurement.

Specifically in the case of paintings, UV fluorescence largely comes from the surface of the top paint layer, and it is barely influenced by the underlying layers. Conservators pursue UVF photography to identify and evaluate the integrity of old varnish layers and to localize inpaints, which generally lack fluorescence, in contrast with the bright appearance of aged varnishes. When the contrast is intense enough, it is possible to implement an automatic segmentation of the UVF image of a retouched painting [24]. This procedure can quicken the workflow for the estimation of the extent of losses, a necessary step in the preparation of condition reports.

Regarding wall paintings, the binding material of a true fresco does not add any fluorescence to the pigment, while the secco, or dry, technique is clearly identified by the fluorescence emission of the binding media used to lay the paint. A characteristic of baroque murals was that the pigments were applied as an opaque mass rather than in a thin, almost translucent layer used in the buon fresco method [25]. This technique allowed impastos of varying thickness in a manner analogous to that of oil painting to be rendered for entire murals. A cycle of such $18^{\text {th }}$ century frescoes was revealed in the Crucifix Chapel of the Mother Church in Aci Sant'Antonio (Sicily) in 2012. The paintings have survived along the corners of an originally square chapel that, in the early $20^{\text {th }}$ century, was altered to acquire the current octagonal plan. The paintings have been recently examined with technical photography [26]. The paintings lack giornate, the line between each day's work, and only pontate, the break between levels of scaffolding, can clearly be seen indicating that a mixture of fresco and secco techniques would have been used. This hypothesis is corroborated by the intense fluorescence of the paint under UV radiation, suggesting the presence of an organic binder (Figure 7).

\section{Ultraviolet reflectance}

As for UVF, since UV radiation interacts mostly just with the superficial layer, the UVR image is specific to the topmost pigments or varnish. UVR is recognized as a useful tool to identify white pigments like titanium white and zinc white, which show a strong UV absorbance band [27] and are thus identifiable for appearing very dark in the UVR image, especially when compared to other white pigments, namely lead white and lithopone, which appear bright (Figures 8-9). A UV false color (UVFC) method has been proposed [28] which, in a manner analogous 

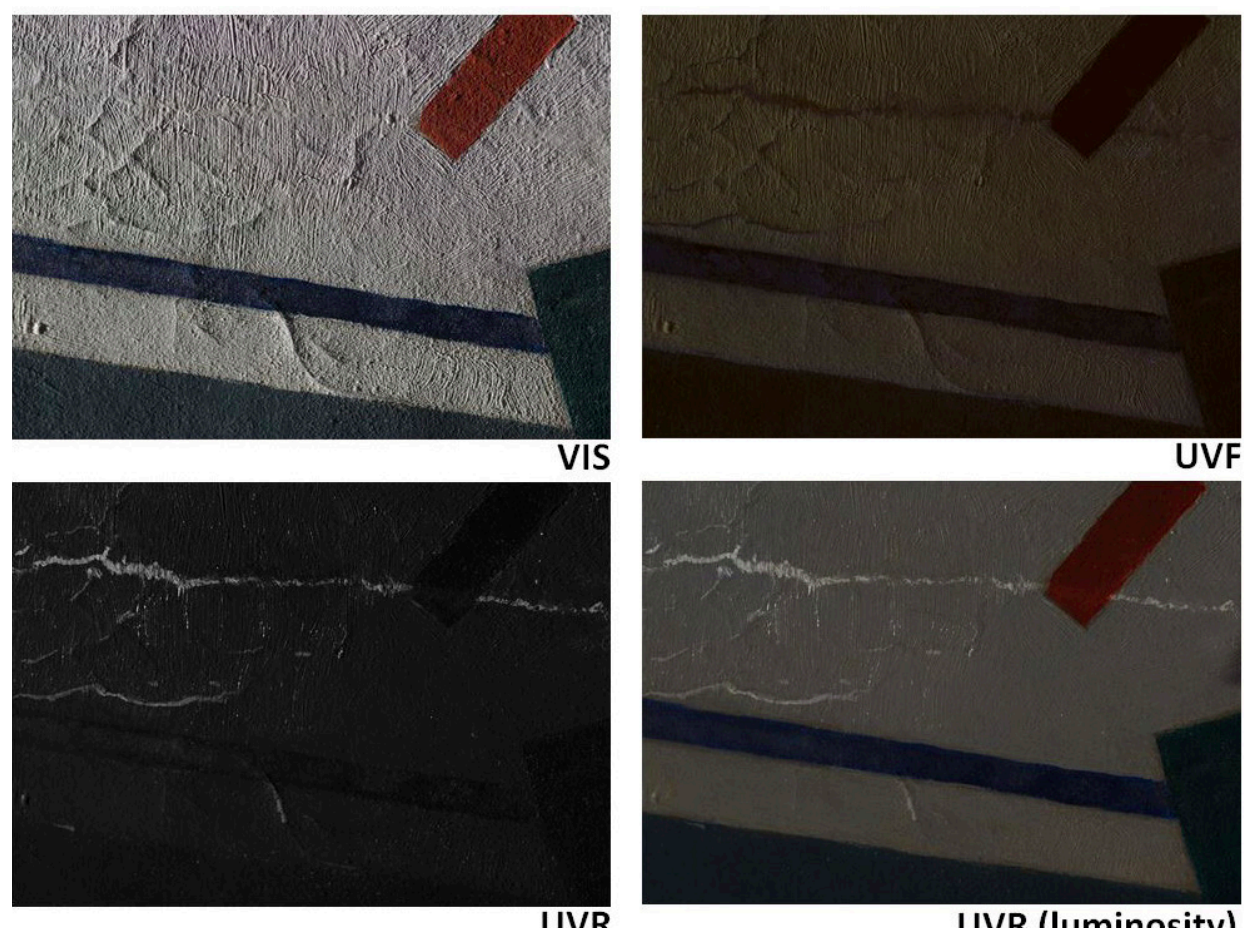

Figure 8. UVF photo shows a characteristic yellow fluorescence, suggesting zinc white for the white pigment used for the background. The UVR image also validates this assignation since the pigment absorbs the UV and appears dark. On the other hand, the restoration interventions on the cracks appear as dark spots in the UVF image, as is normal with recent inpaints. They also are identified in the UVR image, since the inpaints reflect UV. They likely include lithopone, as suggested by the dull UV fluorescence. UVR (Luminosity) (opacity $70 \%$ ) allows a more intuitive reading of the location of the inpaints. Artwork: $20^{\text {th }}$ century oil on canvas, private collection.
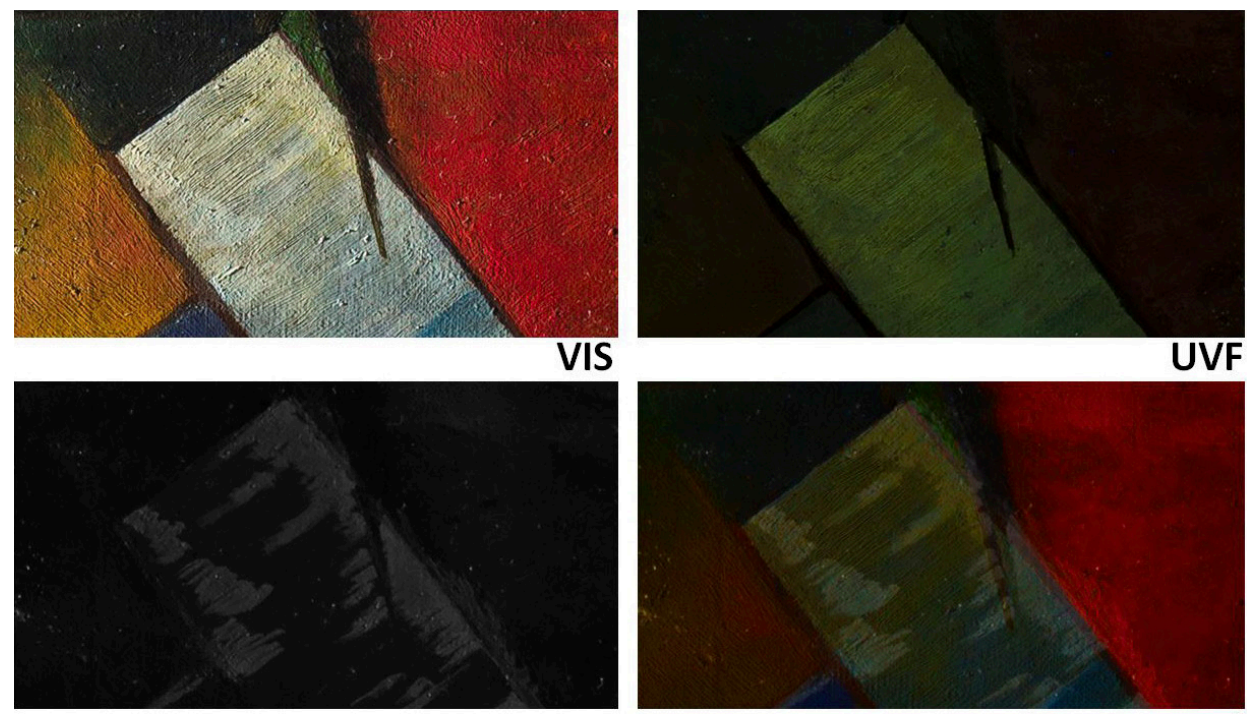

UVR

UVR (Luminosity)

Figure 9. This painting has been heavily restored. Due to more contrast with the original pigments, the retouches can be better identified in the UVR image than in the UVF. UVR (Luminosity) (opacity 70\%) allow the retouches to be read in the context of the actual colours. $20^{\text {th }}$ century oil on canvas, private collection.

to the infrared false color, mixes UV reflectance and VIS channels. Here, it is instead recommended to combine the VIS and UVR images with the luminosity blending mode available in photo editing software such as Adobe Photoshop. This mode keeps the luminance of the upper layer (UVR), and blends it with the hue and saturation of the lower layer (VIS). The resulting image,
UVR (Luminosity), allows a more intuitive reading of the information provided by the UV reflectance photo (Figures 8-9).

Reflectance photography in the shorter UV range does not seem to provide much more useful information. Figure 10 shows the UV reflectance imaging of a pigments checker with 54 historical pigment swatches 

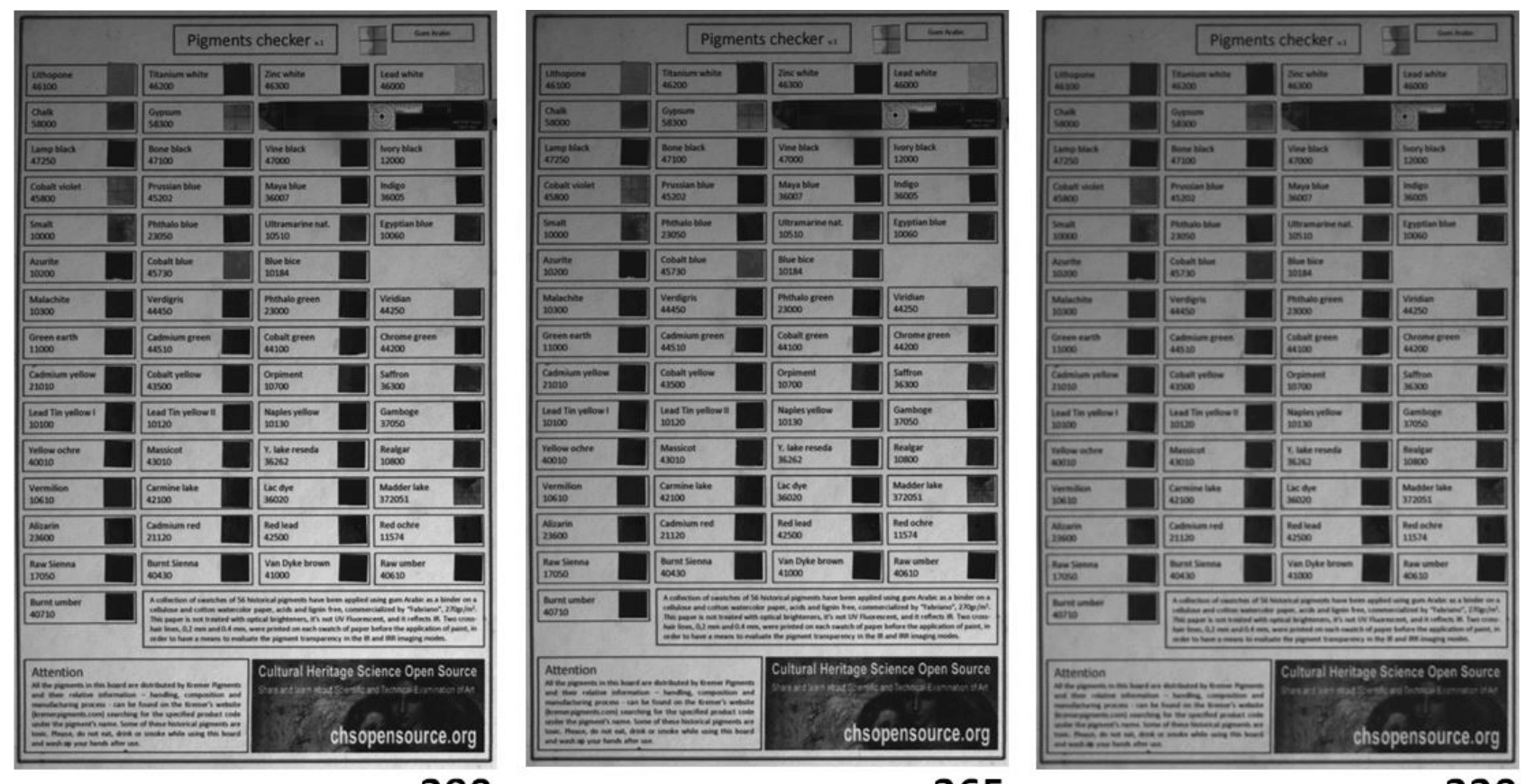

380

365

330

Figure 10. Spectral images in the UV region acquired with SpectroCam UV-VIS and filters in the UV region.

380

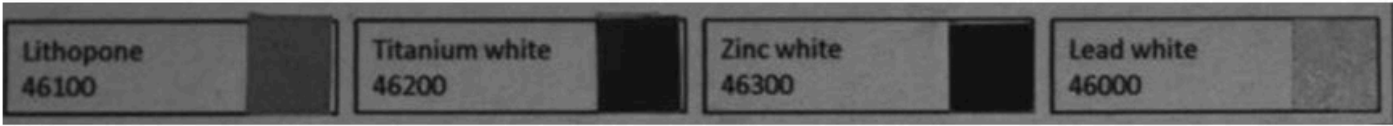

365

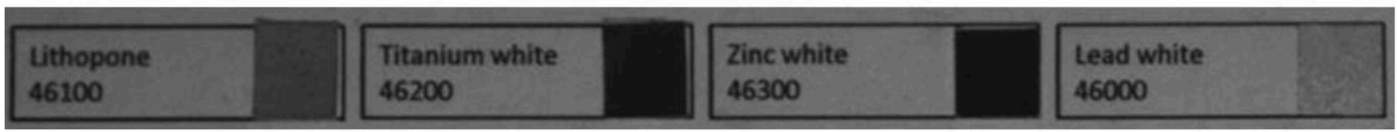

330
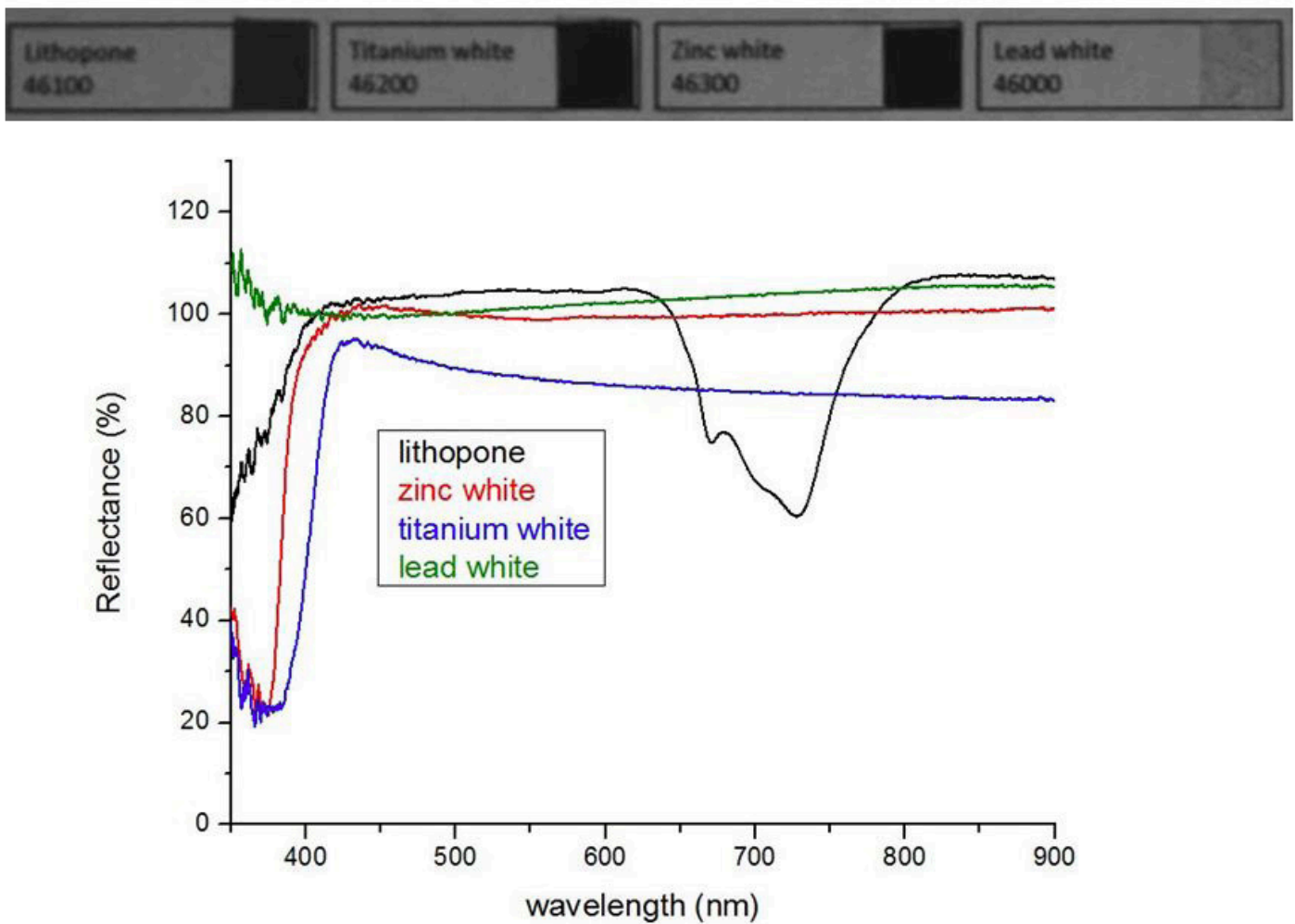

Figure 11. Lithopone has an absorbance band in the shorter UV region, which is measured in the reflectance spectra and can be visualized in the spectral image at $330 \mathrm{~nm}$. 
taken with a PixelTeq UV-VIS camera whose sensitivity is extended to the UV region until about $200 \mathrm{~nm}$. Three spectral images were taken using different bandpass filters (center wavelength / bandwidth): 330/25, 365/19, 380/12. The pigments checker was illuminated with a UV lamp, model B100 AP manufactured by UVP (100 W spot mercury bulb). The only useful information that resulted from this test was the observation of the absorbance band of lithopone in the far UV region (Figure 11).

\section{Conclusions}

This paper has illustrated technical solutions for two photographic methods that use UV radiation: UV fluorescence and UV reflectance. The necessary filters, lenses, lamps, set up, camera and photo calibration have been discussed. Applications have also been reported in order to show the potential of a modified full spectrum camera to perform these technical photographic methods when equipped with the proper accessories. In addition, the luminosity blending mode has been introduced for the first time to make the reading of UVR images more intuitive. It is expected that due to the relatively low cost of the technical photographic equipment, this methodology will be readily accepted for use across the conservation sector. Further research and results are expected from UV-fluorescence multispectral imaging which has proven already [29] to be a promising tool for polychrome art examination.

\section{Acknowledgments}

We thank PixelTeq which kindly provided the SpectroCam UV-VIS and the filters set presented in the paper.

\section{References}

1 Youn, S.; Kim, Y.; Lee, J.; Har, D., 'A study of infrared reflectography for underdrawing detection using a digital camera', in Proceedings of the IASTED International Conference Internet and Multimedia Systems \& Applicatins and Visual Communications, ed. M. Roccetti, Acta Press, Anaheim (2008) 128-134.

2 Falco, C. M., 'High resolution digital camera for infrared reflectography', Review of Scientific Instruments 80 (2009) 071301, doi:10.1063/1.3174431.

3 Dyer, J.; Verri, G.; Cupitt, J., 'Multispectral Imaging in Reflectance and Photo-induced Luminescence Modes: A User Manual', The British Museum, London (2013), www.britishmuseum.org/pdf/charisma-multispectralimaging-manual-2013.pdf.

4 Mairinger, F., 'The ultraviolet and fluorescence study of paintings and manuscripts', in Radiation in Art and Archeometry, ed. D. C. Creagh and D. A. Bradley, Elsevier, (2000) 56-75, doi:10.1016/B978-044450487-6/50050-X.

5 Cosentino, A.; Stout, S.; Scandurra, C., 'Innovative imaging techniques for examination and documentation of mural paintings and historical graffiti in the catacombs of San Giovanni, Syracuse', International Journal of Conservation
Science 6(1) (2015) 23-34, http://www.ijcs.uaic.ro/public/ IJCS-15-03_Cosentino.pdf.

6 Verhoeven, G., 'Imaging the invisible using modified digital still cameras for straightforward and low-cost archaeological near-infrared photography', Journal of Archaeological Science 35 (2008) 3087-3100, doi:10.1016/j. jas.2008.06.012.

7 Cosentino, A. 'Identification of pigments by multispectral imaging; a flowchart method', Heritage Science 2:8 (2014) doi:10.1186/2050-7445-2-8.

8 Warda, J.; Frey, F.; Heller, D.; Kushel, D.; Vitale, T.; Weaver, G., 'Ultraviolet photography', in AIC Guide to Digital Photography and Conservation Documentation, $2^{\text {nd }}$ ed., American Institute for Conservation of Historic and Artistic Works, Washington DC (2011).

9 Pelagotti, A.; Pezzati, L.; Bevilacqua, N.; Vascotto, V.; Reillon, V.; Daffara, C., 'A study of UV fluorescence emission of painting materials', in $8^{\text {th }}$ International Conference on Non-Destructive Testing and Microanalysis for the Diagnostics and Conservation of the Cultural and Environmental Heritage, Lecce, Italy (2005), http://www. inoa.it/home/lella/pdf/Art2005_A\%20study\%20of\%20 UV\%20fluorescence $\% 20$ emission $\% 20$ of $\% 20$ painting $\% 20$ ma\% 85.pdf.

10 Pelagotti, A.; Pezzati, L.; Piva, A.; Del Mastio, A., 'Multispectral UV fluorescence analysis of painted surfaces', in Proceedings of 14th European signal processing conference (EUSIPCO), Firenze, Italy (2006).

11 Verri, G.; Comelli, D.; Cather, S.; Saunders, D.; Piqué, F., 'Post-capture data analysis as an aid to the interpretation of ultraviolet-induced fluorescence images', in Computer Image Analysis in the Study of Art, ed. D. G. Stork and J. Coddington, SPIE, San Jose (2008) 681001-681012, doi:10.1117/12.764463.

12 Verri, G.; Clementi, C.; Comelli, D.; Cather, S.; Piqueé F. 'Correction of ultraviolet-induced fluorescence spectra for the examination of polychromy', Applied Spectroscopy 62(12) (2008) 1295-1302, doi:10.1366/0003702087868222 96.

13 Feller, R. L., Accelerated Aging. Photochemical and Thermal Aspects, The Getty Conservation Institute, Los Angeles (1994).

14 Cosentino, A.; Caggiani, M. C.; Ruggiero, G.; Salvemini, F., 'Panoramic multispectral imaging: training and case studies', Bulletin - Association Professionelle de Conservateurs-Restaurateurs d'Oeuvres d'Art (2014) 7-11, http://www.brk-aproa.org/uploads/bulletins/BULLETIN\%20 2-14\%20kleur.pdf.

15 Cosentino, A. 'A practical guide to panoramic multispectral imaging', e-Conservation Magazine 25 (2013) 64-73, http:// www.e-conservationline.com/content/view/1100/

16 'AIC PhD Targets', Robin Myers Imaging, http://www. rmimaging.com/aic_phd.html (accessed 29-5-2015).

17 Pereira, L. B., 'UV Fluorescence photography of works of art: replacing the traditional UV cut filters with interference filters', International Journal of Conservation Science, 1(3) (2013) 161-166, http://ijcs.uaic.ro/pub/IJCS-10-16-Bravo. pdf.

18 Rorimer, J.J., Ultraviolet Rays and Rheir Use in the Examination of Works of Art, Metropolitan Museum of Art, New York (1931).

19 Buzit-Tragni, C. B., 'The use of ultraviolet-induced visible fluorescence for examination of photographs', in $A$. W. Mellow Fellow, Advanced Residency Program in Photograph Conservation, Image Permanence Institute, Rochester (2005).

20 Baldia, C. M.; Jakes, K. A., 'Photographic methods to detect colourants in archaeological textiles', Journal of Archaeological Acience 34(4), (2007) 519-525, doi:10.1016/j.jas.2006.06.010. 
21 Isacco, E.; Darrah, J., 'The ultraviolet-infrared method of analysis, a scientific approach to the study of Indian miniatures', Artibus Asiae 53(3-4) (1993) 470-491, doi:10.2307/3250528.

22 René de la Rie, E., 'Fluorescence of Paint and Varnish Layers (Part I)', Studies in Conservation 27(1) (1982) 1-7, doi:10.1179/sic.1982.27.1.1.

23 Comelli, D.; Nevin, A.; Brambilla, A.; Osticioli, I.; Valentini, G.; Toniolo, L.; Cubeddu, R., 'On the discovery of an unusual luminescent pigment in Van Gogh's painting "Les Bretonnes et le Pardon de Pont Aven", Applied Physics A, 106(1) (2012) 25-34, doi:10.1007/s00339-011-6665-9.

24 Cosentino, A.; Stout, S., 'Photoshop and multispectral imaging for art documentation', e-Preservation Science 11 (2014) 91-98, http://www.morana-rtd.com/epreservationscience/2014/ePS_2014_a11_Cosentino.pdf.

25 Mora, P.; Mora, L.; Philippot, P, Conservation of Wall Paintings, Butterworths, London (1984).

26 Cosentino, A.; Stout, S.; Di Mauro, R.; Perondi, C., 'The Crucifix Chapel of Aci Sant'Antonio: newly discovered frescoes', Archeomatica 2 (2014) 36-42, http://issuu.com/ geomedia/docs/archeomatica_2_2014?e=1225360/9272033.

27 Cosentino, A., 'FORS spectral database of historical pigments in different binders', e-conservation Journal, 2, (2014) 57-68, http://e-conservation.org/issue-2/36-FORSspectral-database.
28 Aldrovandi, A.; Buzzegoli, E.; Keller, A.; Kunzelman, D., 'Investigation of painted surfaces with a reflected UV false color technique', in Art'05 - 8th International Conference on "Non Destructive Investigations and Micronalysis for the Diagnostics and Conservation of the Cultural and Environmental Heritage, Lecce (2005).

29 Comelli, D.; Valentini, G.; Nevin, A.; Farina, A.; Toniolo, L.; Cubeddu, R., 'A portable UV-fluorescence multispectral imaging system for the analysis of painted surfaces', Review of Scientific Instruments 79(8) (2008) 086112, doi: 10.1063/1.2969257.

Received:: 29 May 2015

Revised: 5 July 2015

Accepted: 13 July 2015

Online: 24 July 2015

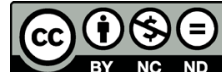

This work is licensed under the Creative Commons Attribution-NonCommercial-NoDerivs 3.0 Unported License.

To view a copy of this license, visit http://creativecommons.org/licenses/by-nc-nd/3.0/deed.pt. 